\section{LACE RESEARCH ASSOCIATION}

\section{NEW CENTRE AND LABORATORIES}

$\mathrm{T}$

HE new centre and laboratories of the Lace Research Association at Glaisdale Drive, Bilborough, Nottingham, were formally opened on May 15 by Sir Cecil Weir, and after the ceremony a large number of members of the Association and their guests inspected the work being carried out in the laboratories.

The lace industry of Great Britain is a small but highly specialized, and economically important, industry situated mainly in Nottingham and the surrounding districts; all types of lace are manufactured there, but centres are also to be found near Kilmarnock in Scotland, where the product is lace furnishings, and in the west of England, where plain nets are made. There are very few large firms, the industry consisting in general of small unit firms, some three hundred in number, and the average size is of the order of ten machines. The working force varies between ten and fifteen thousand employees, of which, compared with the other textile industries, a very high proportion is made up of male workers. The conversion value of lace from the raw fibre to the finished fabric is exceedingly high; the trade is worth £10-15 million a year and is concentrated mainly on the export market, certain sections exporting as much as 98 per cent of their products.

The industry consists of six separate branches manufacturing the following types of product : plain net section-all types of plain and figured nets, including dress nets, tulle, mosquito nets, sand-fly netting, etc.; leavers lace section-fancy laces, hair nets, veilings, trimming laces, etc. ; lace furnishings section-curtains, table and bed furnishings, etc.; warp lace section--lace produced on a multi-thread warp lace knitting-machine; barmen sectionnarrow lace and braiding ; and embroidery sectionpattern lace produced on multi-needle 'schiffli' machines, either on a base of plain net or on a dissoluble fabric. Nearly all the common textile fibres, both natural and synthetic, are used, or can be used, in the industry, but the principal fibre is, of course, cotton. An important subsidiary part of the industry is that concernod with the dyeing, dressing and finishing of lace; these operations are confined to a small number of firms which have the necessary specialized skill, experience and machinery.

The building of lace machines is a highly specialized branch of engineering, and Nottingham is naturally the world centre. In general, the machines are very large, those in the leavers section of the industry being of the order of 200 in. in width, while in the lace furnishing section there are several producing lace of up to $480 \mathrm{in}$. in width.

The idea of setting up a research organization for the lace industry was first mooted in 1943, and in March 1944 a research committee was formed by the Federation of Lace and Embroidery Employers' Association. From this development a Lace Federation Research Council was started, which was recognized by the Department of Scientific and Industrial Research as a grant-earning body, and a small research staff was assembled in temporary premises in Nottingham. After further discussions with all the interested trade bodies, it was decided to take advantage of the Industrial Organization and Development Act and to raise money for the formation of a research organization by means of a statutory levy from all the manufacturing sections of the industry. The Lace Research Association was finally incorporated in October 1949, and took over, in expanded form, the functions of the Lace Federation Research Council. The Association is financed in part by the proceeds of the statutory levy, in part by subscriptions and in part by a government grant based on the income from industry. Generally speaking, it is very well supported by the trade, and its total basic inoome is of the order of $£ 17,000$ a year.

The new building of the Association consists of administrative and laboratory space amounting to approximately $3,800 \mathrm{sq}$. ft. 'The front portion contains the library and council room, director's office, general office and textile-testing room. In the laboratory wing are physics and chemistry laboratories, a dark room, engineering workshop, operational research section, store rooms and offices, and a small canteen and kitchen; this wing is built so as to allow for future expansion, the partitioning being easily altered, and running below the main corridor is a trench carrying all the necessary services, with subsidiary trenches into the individual laboratories. To the rear of the site is a separate building with floor space of $2,000 \mathrm{sq}$. ft. which holds full-scale narrow-width lace machines and certain auxiliary equipment, and in which experimental and development work on the production side may be undertaken; this building is well insulated and is electrically heated with thermostatic control to maintain a steady temperature. The research work in the laboratory wing has up to now been chiefly concerned with two problems. In the first, a new type of Jacquard string known as 'Lacra' string has been developed which does not change appreciably in length with varying humidity (caused by changes in the weather). These strings are of high-quality linen thread and are used in the Jacquard pattern-forming mechanism of lace-furnishing machines. As the strings are of different length, a certain percentage change due to variation in the humidity will cause different overall changes in length and the pattern will be distorted. The new string has now been in service on a number of machines for some time and is proving highly successful. The other research development has been the production of a new lubricant in place of the powdered graphite normally used for lubricating the fine working parts of a lace machine. Graphite has the disadvantage that, being black, it causes considerable dirt in the factory and soils the lace. A new lubricant, the composition of which is at present a secret, has been developed which allows the production of fabrics which are quite white.

As might be expected, a cordial spirit exists between the research staff, headed by J. C. MacCallum as director of research and secretary of the Association, and the University of Nottingham. Three Nottingham professors serve on the council of the Association, and one of them, Prof. L. F. Bates, is vice-chairman of the Research Control Committee. Relations are also maintained with the Nottingham and District Technical College. This co-operation between the research organization of an industry that has a very strong regional background with the educational and technical-training services of that region is certainly a very happy feature of the Association, and it augurs well for the quality of the scientific and technical work that can be expected from the new laboratories. 